\title{
Correlation between insulin resistance and breast elasticity heterogeneity measured by shear wave elastography in premenopausal women - a pilot study
}

\author{
Pawel Rzymski $i^{1}$, Piotr J. Wysocki², Witold Kycler ${ }^{3}$ Tomasz Opala ${ }^{1}$
}

1Department of Mother's and Child's Health, Poznan University of Medical Sciences, Gynaecological and Obstetrical University Hospital, Poznan, Poland

2Department of Chemotherapy, Greater Poland Cancer Centre, Poznan University of Medical Sciences, Poland

${ }^{3}$ Department of Oncological Surgery, Greater Poland Cancer Centre, Poznan, Poland

Submitted: 22 February 2011

Accepted: 26 September 2011

Arch Med Sci 2011; 7, 6: 1017-1022

DOI: 10.5114/AOMS.2011.26614

Copyright (๐) 2011 Termedia \& Banach

\section{Abstract}

Introduction: Recent studies have demonstrated a strong correlation between obesity, insulin resistance, increased insulin and insulin-like growth factor levels and the risk of breast cancer. Our study was aimed at exploring correlations between glucose, insulin, insulin resistance, obesity and quantitatively estimated breast elasticity in healthy women.

Material and methods: The pilot study included 37 premenopausal women aged 22-45 years who underwent B-mode sonography and real-time shear wave elastography. Blood was collected for fasting insulin and glucose, and HOMA insulin resistance index was calculated.

Results: The mean elasticity of glandular and fatty tissue measured in both breasts was $12.5 \pm 3.5 \mathrm{kPa}$ and $10.9 \pm 3.7 \mathrm{kPa}$ respectively. Insulin levels did not correlate with glandular tissue elasticity ( $\mathrm{Rs}=-0.23, p=0.15$ ), but nearly correlated with fat tissue elasticity ( $\mathrm{Rs}=-0.30, p=0.06$ ), in outer quadrants significantly (Rs $=-0.38, p=0.02$ ). Interestingly, a strong correlation of insulin and insulin resistance with elasticity heterogeneity was found in fatty tissue (Rs $=-0.59, p<0.001$ and $\mathrm{Rs}=-0.60, p<0.001$ respectively). The heterogeneity of fatty tissue but not glandular elasticity also correlated with body mass index. Conclusions: Insulin levels and insulin resistance correlate with breast fat tissue heterogeneity, but their role in breast pathology remains unclear.

Key words: breast elastography, insulin, glucose, insulin resistance, obesity.

\section{Introduction}

Recent studies have demonstrated a strong correlation between obesity, insulin resistance, increased insulin and insulin-like growth factor levels and the risk of breast cancer. Beside its metabolism-regulating properties on a whole organism level, insulin exerts mitogenic effects in vitro and has also been shown to inhibit apoptosis in various breast cancer cell lines [1]. It has been generally accepted that such metabolic disorders as hyperglycaemia and chronic hyperinsulinaemia may be important for development of breast cancer. Additionally, another metabolic condition, obesity, has been demonstrated to increase breast cancer risk in postmenopausal, but not in premenopausal women [2]. Insulin may also

\author{
Corresponding author: \\ Pawel Rzymski MD, PhD \\ Department of Mother's \\ and Child's Health \\ Poznan University \\ of Medical Sciences \\ Gynaecological \\ and Obstetrical \\ University Hospital \\ 33 Polna, 60-535 Poznan \\ Poland \\ Phone: +48 605393096 \\ Fax: +48 618419618 \\ E-mail: \\ parzymsk@gpsk.am.poznan.pl
}


indirectly promote breast cancer development, via upregulation and modulation of bioavailability of IGF-1 (insulin growth factor-1) and IGF-2 (insulin growth factor-2), especially in the tumour microenvironment [3]. It has been proposed that insulin and IGF-1 act directly as paracrine and autocrine growth factors for breast cancer cells [4] via activation of $\mathrm{PI} 3 \mathrm{~K} / \mathrm{AKT} / \mathrm{mTOR}$ and RAS/RAF/MAPK signalling pathways. Additionally, both factors may indirectly increase the risk of breast cancer via stimulation of proliferation of normal human mammary cells, leading to increased breast density. Mammographic breast density has been demonstrated to be an important risk factor for breast cancer. In women, a simultaneous increase of female and growth hormones (e.g. oestrogen, insulin, IGF-1) correlates with the mass of the mammary gland. In postmenopausal women aromatase located within fatty tissue is solely responsible for production of oestrogens [4, 5]. Thus high activity of aromatase in postmenopausal obese women is responsible for high systemic oestrogen levels, which directly correlate with the risk of development of hormonedependent breast cancer. The above described interactions explain the phenomenon of increased frequency of hormone-dependent breast cancer in obese postmenopausal women [4]. Insulin may also be responsible for increased oestrogen levels, since insulin has been demonstrated to decrease the systemic sex hormone binding globulin (SHBG) levels [6]. Accordingly, insulin, obesity and insulin resistance altogether represent important risk factors for breast cancer [4, 7]. In breast cancer patients obesity is a negative prognostic factor irrespectively of the patient's menopausal status [4].

As mentioned previously, mammographic breast density represents one of the risk factors for breast cancer. Dense breasts imply a 4-6-fold increase of the risk of breast cancer [8].

Despite the above-mentioned interactions between insulin, glucose, obesity and mammographic breast density and breast cancer incidence, to our best knowledge virtually no studies have analysed these factors in the context of breast elasticity. Breast sonoelastography is a relatively new but rapidly evolving diagnostic modality. Our study was aimed at exploring correlations between glucose, insulin, insulin resistance, obesity and quantitatively estimated breast elasticity in healthy women. Providing some insight into the relationship between metabolic parameters and breast elasticity may become useful information improving interpretation of sonoelastograms in clinical practice.

\section{Material and methods}

The current study included 37 premenopausal women aged 22-45 years who underwent B-mode sonography in the Gynaecological and Obstetrical
University Hospital in Poznan, Poland. All patients underwent a routine diagnostic procedure due to menstrual disorders. Patients underwent gynaecological examination and blood samples were collected on the $7^{\text {th }}$ day of the menstrual cycle for estimation of insulin and glucose levels. The day was chosen because of ultrasound examination. Because of menstrual disorders in all patients, follicle stimulating hormone (FSH), lutropin (LH), oestradiol and prolactin levels were determined. Based on glucose and insulin levels, the insulin resistance was calculated according to the HOMA (Homeostatic Model Assessment) formula: $\mathrm{HOMA}_{\mathrm{IR}}=$ insulin $(\mathrm{mU} / \mathrm{dl}) \times$ glucose $(\mathrm{mg} / \mathrm{dl}) / 40.5$.

The study was performed between November 2009 and June 2010. All subjects filled a standard questionnaire with general medical, obstetrical and breast history. Patients underwent B-mode breast sonography (Aixplorer Ultrasound System, SuperSonic Imagine SA, France), which revealed no abnormalities, and were classified as BIRADS (Breast Imaging Reporting and Data System) 1. The ultrasound examination as well as sonoelastography were performed by a highly experienced gynaecologist (P.R.). Equipment used in this study makes possible normal ultrasound scanning with a linear probe (at $15 \mathrm{MHz}$ ) and real-time sonoelastography. The methodology was based on the generation of a remote radiation force by focused ultrasonic beams. Each pushing beam generates a remote vibration that results in transient shear wave propagation. Several pushing beams transmitted at different depths result in a quasi-plane shear wave front which propagates through the whole imaging region of interest (ROI) [1, 2]. Following the standard B-mode ultrasound scanning, the second part of the examination was performed in the scheme designed for this study. The left and right breast were divided into 8 quadrants and 8 scans of normal breast tissue from both breasts were acquired with elastography mode.

During acquisition a single scan of the ROI was set to include subcutaneous fat at the top and the margin of the pectoral muscle at the bottom. The best greyscale scan was used to identify glandular and fat tissue. All elastography scans included measurements with $2 \mathrm{~mm}$ to $3 \mathrm{~mm}$ diameter Q-box (area of elasticity measurement in $\mathrm{kPa}$ ) in glandular and fat tissue. The chosen area was typical and representative for glandular and fatty tissue in greyscale ultrasound and Q-box diameter depended on the tissue diameters. Parameters included mean elasticity in Q-box, minimal and maximal elasticity in Q-box, and standard deviation (SD), as supplied by ultrasound device software. Additionally we calculated the heterogeneity of the sonoelasticity map in Q-Box, which represents a colourcoded map of elasticity. For this purpose we 
calculated the minimum to maximum range of this map (heterogeneity minimum-maximum) and divided it by the minimal elasticity value (heterogeneity as percent of minimal value) and mean value (heterogeneity as percent of mean value). From all 37 patients, 296 elastography scans were achieved from 8 quadrants. For analysis we calculated glandular to fatty tissue ratio and we also grouped breast quadrants into inner (scans 3, 4, 5 and 6) and outer (scans 1, 2, 7 and 8).

All data were stored in an MS Excel spreadsheet (Microsoft Corp, USA) and analysed with SigmaStat 3.1 (Jandel Corp, USA). The normal distribution was confirmed by Kolmogorov-Smirnov test. The correlation between parameters were checked by Spearman's test. Values $p$ less than 0.05 were considered significant. We used two-tailed tests to examine the significance in both previously unknown directions. The study was approved by the local bioethics committee and patients gave their written consent.

\section{Results}

\section{Analysis of breast tissue elasticity}

The mean elasticity of glandular and fatty tissue measured in both breasts was $12.5 \pm 3.5 \mathrm{kPa}$ and
$10.9 \pm 3.7 \mathrm{kPa}$ respectively. Glandular tissue elasticity in inner and outer quadrants was $14.6 \pm 4.8 \mathrm{kPa}$ and $10.3 \pm 3.1 \mathrm{kPa}$ respectively. Analogically, fatty tissue elasticity in inner and outer quadrants was $12.7 \pm 5.3 \mathrm{kPa}$ and $9.0 \pm 3.2 \mathrm{kPa}$ respectively.

\section{Correlation of breast elasticity with metabolic parameters}

Insulin levels did not correlate with glandular tissue elasticity (Rs $=-0.23, p=0.15$ ), but nearly correlated with fat tissue elasticity $(\mathrm{Rs}=-0.30$, $p=0.06)$. This tendency referring to fat tissue was different in inner and outer quadrants, where correlations were insignificant ( $\mathrm{Rs}=-0.24, p=0.16$ ) and significant (Rs $=-0.38, p=0.02$ ) respectively. The HOMA index did not correlate with glandular tissue elasticity and reached borderline significance in fatty tissue ( $\mathrm{Rs}=-0.31, p=0.055$ ).

\section{Analysis of heterogeneity of elasticity}

As the next step we analysed heterogeneity of the elasticity map in Q-box. The results of the correlations with insulin, glucose, and HOMA index are presented in Table I. Interestingly, a strong correlation of insulin and insulin resistance was found in fatty tissue. The correlation is presented in Fig-

Table I. Correlations of breast elastographic parameters with insulin, glucose and insulin resistance

\begin{tabular}{|c|c|c|c|}
\hline Elastographic parameter & Insulin [mU/ml] & Glucose [mg/dl] & $\begin{array}{l}\text { Insulin resistance } \\
(\text { HOMA IR)* }\end{array}$ \\
\hline \multicolumn{4}{|l|}{ Glandular tissue } \\
\hline Heterogeneity (min-max) [kPa] & $\begin{aligned} \mathrm{Rs} & =-0.22 \\
p & =0.18\end{aligned}$ & $\begin{aligned} \mathrm{Rs} & =-0.10 \\
p & =0.54\end{aligned}$ & $\begin{aligned} \mathrm{Rs} & =-0.22 \\
p & =0.19\end{aligned}$ \\
\hline Heterogeneity of inner quadrants (min-max) [kPa] & $\begin{aligned} \mathrm{Rs} & =-0.15 \\
p & =0.35\end{aligned}$ & $\begin{aligned} \mathrm{Rs} & =-0.07 \\
p & =0.67\end{aligned}$ & $\begin{aligned} \mathrm{Rs} & =-0.15 \\
p & =0.37\end{aligned}$ \\
\hline Heterogeneity of outer quadrants (min-max) [kPa] & $\begin{aligned} \mathrm{Rs} & =-0.10 \\
p & =0.55\end{aligned}$ & $\begin{aligned} \mathrm{Rs} & =-0.01 \\
p & =0.93\end{aligned}$ & $\begin{aligned} \mathrm{Rs} & =-0.09 \\
p & =0.56\end{aligned}$ \\
\hline Heterogeneity (\% of mean) & $\begin{array}{c}\text { Rs }=0.08 \\
p=0.59\end{array}$ & $\begin{aligned} \mathrm{Rs} & =-0.05 \\
p & =0.76\end{aligned}$ & $\begin{array}{c}\mathrm{Rs}=0.08 \\
p=0.61\end{array}$ \\
\hline Heterogeneity (\% of minimum) & $\begin{aligned} \mathrm{Rs} & =0.08 \\
p & =0.61\end{aligned}$ & $\begin{aligned} \mathrm{Rs} & =-0.07 \\
p & =0.65\end{aligned}$ & $\begin{array}{c}\mathrm{Rs}=0.07 \\
p=0.63\end{array}$ \\
\hline \multicolumn{4}{|l|}{ Fat tissue } \\
\hline Heterogeneity (min-max) [kPa] & $\begin{array}{c}\mathrm{Rs}=-0.59 \\
p<0.001\end{array}$ & $\begin{aligned} \mathrm{Rs} & =-0.256 \\
p & =0.125\end{aligned}$ & $\begin{array}{c}\mathrm{Rs}=-0.60 \\
p<0.001\end{array}$ \\
\hline Heterogeneity of inner quadrants (min-max) [kPa] & $\begin{array}{c}\text { Rs }=-0.46 \\
p=0.004\end{array}$ & $\begin{array}{c}\mathrm{Rs}=-0.165 \\
p=328\end{array}$ & $\begin{array}{c}\mathrm{Rs}=-0.45 \\
p=0.005\end{array}$ \\
\hline Heterogeneity of outer quadrants (min-max) [kPa] & $\begin{array}{c}\mathrm{Rs}=-0.48 \\
p=0.002\end{array}$ & $\begin{aligned} \mathrm{Rs} & =-0.237 \\
p & =0.157\end{aligned}$ & $\begin{array}{c}\mathrm{Rs}=-0.50 \\
p=0.001\end{array}$ \\
\hline Heterogeneity (\% of mean) & $\begin{array}{c}\mathrm{Rs}=-0.38 \\
p=0.022\end{array}$ & $\begin{array}{c}\text { Rs }=-0.17 \\
p=0.314\end{array}$ & $\begin{aligned} \mathrm{Rs} & =-0.383 \\
p & =0.019\end{aligned}$ \\
\hline Heterogeneity (\% of minimum) & $\begin{array}{c}\mathrm{Rs}=-0.39 \\
p=0.016\end{array}$ & $\begin{aligned} \mathrm{Rs} & =-0.17 \\
p & =0.29\end{aligned}$ & $\begin{array}{c}\text { Rs }=-0.41 \\
p=0.013\end{array}$ \\
\hline
\end{tabular}

*HOMA IR = insulin $[\mathrm{mU} / \mathrm{dl}] \times$ glucose $[\mathrm{mg} / \mathrm{dl}] / 40.5$ 


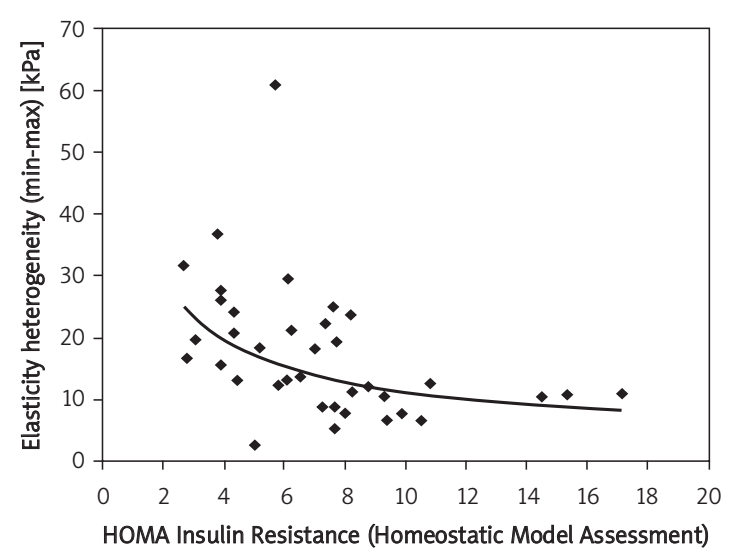

Figure 1. Correlation between elasticity heterogeneity and insulin resistance in fatty tissue

ures 1 and 2. Correlations of elasticity heterogeneity and other breast cancer risk factors such as body mass index (BMI), lack of lactation or deliveries are presented in Table II.

\section{Discussion}

Mammographic breast density is one of the strongest risk factors for breast cancer [8]. It reflects variations in the tissue composition of the breast, and is associated positively with collagen and epithelial and non-epithelial cells, and negatively with fat. Several cross-sectional studies have been carried out

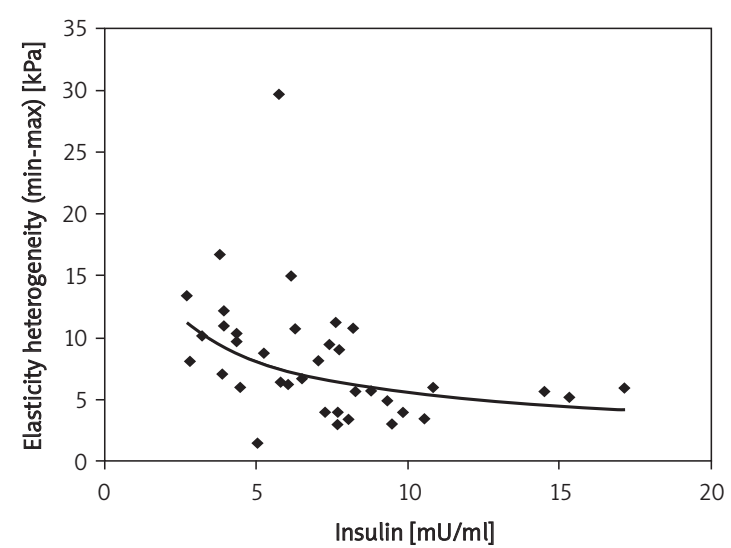

Figure 2. Correlation between elasticity heterogeneity and insulin levels in fatty tissue

in order to evaluate the influence of various factors on this condition. Data from these studies demonstrate that the extent of mammographic breast density may be associated with increased levels of IGF-1 and decreased levels of IGF binding protein-3 (IGFBP-3) in premenopausal women [9, 10].

The influence of insulin and insulin resistance on mammographic breast density is controversial. Wolin et al. did not find any correlation between insulin levels, HOMA index and breast mammographic density, and demonstrated only a modest correlation between sedentary time (which usual-

Table II. Correlations of breast elastographic parameters with other breast cancer risk factors

\begin{tabular}{|c|c|c|c|}
\hline Elastographic parameter & $\begin{array}{c}\text { BMI } \\
{\left[\mathrm{kg} / \mathrm{m}^{2}\right]}\end{array}$ & $\begin{array}{c}\text { Age of first delivery } \\
\text { [years] }\end{array}$ & $\begin{array}{l}\text { Lactation } \\
\text { [months] }\end{array}$ \\
\hline \multicolumn{4}{|l|}{ Glandular tissue } \\
\hline Heterogeneity (min-max) [kPa] & $\begin{array}{c}\mathrm{Rs}=-0.38 \\
p=0.017\end{array}$ & $\begin{aligned} \mathrm{Rs} & =-0.19 \\
p & =0.58\end{aligned}$ & $\begin{aligned} \mathrm{Rs} & =-0.08 \\
p & =0.62\end{aligned}$ \\
\hline Heterogeneity of inner quadrants (min-max) [kPa] & $\begin{array}{c}\mathrm{Rs}=-0.22 \\
p=0.17\end{array}$ & $\begin{aligned} \mathrm{Rs} & =-0.01 \\
p & =0.94\end{aligned}$ & $\begin{aligned} \mathrm{Rs} & =-0.13 \\
p & =0.43\end{aligned}$ \\
\hline Heterogeneity of outer quadrants (min-max) [kPa] & $\begin{aligned} \mathrm{Rs} & =-0.20 \\
p & =0.23\end{aligned}$ & $\begin{aligned} \text { Rs } & =-0.42 \\
p & =0.22\end{aligned}$ & $\begin{array}{c}\mathrm{Rs}=0.03 \\
p=0.81\end{array}$ \\
\hline Heterogeneity (\% of mean) & $\begin{aligned} \mathrm{Rs} & =-0.05 \\
p & =0.76\end{aligned}$ & $\begin{aligned} \text { Rs } & =-0.02 \\
p & =0.91\end{aligned}$ & $\begin{array}{c}\mathrm{Rs}=0.13 \\
p=0.41\end{array}$ \\
\hline Heterogeneity (\% of minimum) & $\begin{aligned} \mathrm{Rs} & =-0.05 \\
p & =0.76\end{aligned}$ & $\begin{aligned} \mathrm{Rs} & =-0.02 \\
p & =0.91\end{aligned}$ & $\begin{aligned} \mathrm{Rs} & =-0.14 \\
p & =0.39\end{aligned}$ \\
\hline \multicolumn{4}{|l|}{ Fat tissue } \\
\hline Heterogeneity (min-max) [kPa] & $\begin{array}{c}\mathrm{Rs}=-0.59 \\
p<0.001\end{array}$ & $\begin{aligned} \text { Rs } & =-0.39 \\
p & =0.26\end{aligned}$ & $\begin{aligned} \mathrm{Rs} & =-0.08 \\
p & =0.59\end{aligned}$ \\
\hline Heterogeneity of inner quadrants (min-max) [kPa] & $\begin{array}{c}\mathrm{Rs}=-0.45 \\
p=0.005\end{array}$ & $\begin{aligned} \mathrm{Rs} & =-0.29 \\
p & =0.40\end{aligned}$ & $\begin{aligned} \mathrm{Rs} & =-0.08 \\
p & =0.61\end{aligned}$ \\
\hline Heterogeneity of outer quadrants (min-max) $[\mathrm{kPa}]$ & $\begin{array}{c}\text { Rs }=-0.47 \\
p=0.003\end{array}$ & $\begin{aligned} \mathrm{Rs} & =-0.14 \\
p & =0.67\end{aligned}$ & $\begin{aligned} \mathrm{Rs} & =-0.07 \\
p & =0.66\end{aligned}$ \\
\hline Heterogeneity (\% of mean) & $\begin{array}{c}\text { Rs }=-0.24 \\
p=0.14\end{array}$ & $\begin{array}{l}\mathrm{Rs}=0.10 \\
p=0.77\end{array}$ & $\begin{aligned} \mathrm{Rs} & =-0.09 \\
p & =0.61\end{aligned}$ \\
\hline Heterogeneity (\% of minimum) & $\begin{array}{c}\mathrm{Rs}=-0.26 \\
p=0.11\end{array}$ & $\begin{array}{c}\mathrm{Rs}=0.17 \\
p=0.61\end{array}$ & $\begin{aligned} \mathrm{Rs} & =-0.05 \\
p & =0.74\end{aligned}$ \\
\hline
\end{tabular}


ly correlates with obesity/insulin resistance and some poor dietary practices) and breast density [11] In that study, breast density was increased by $0.25 \%$ for every 100 min more spent sitting. Diorio et al. demonstrated that elevated levels of C-peptide (a marker of insulin secretion) as a single factor correlated with decreased breast density; however, the significance was lost when adjusted for adiposity [12]. These observations were confirmed in other studies, which generally showed that just elevated insulin or C-peptide levels do not increase the risk of breast cancer $[13,14]$. However, Malin et al. found a strong correlation between insulin resistance and breast cancer risk in a dose-dependent manner. This relation was constant even when women were analysed separately according to their menopausal status [7]. This observation has been confirmed in a recent prospective study which demonstrated that insulin resistance and obesity significantly influence risk of breast cancer development and progression [15].

Metabolic syndrome is a condition involving beside hypertension various metabolic disorders such as abdominal obesity, high blood glucose levels, impaired glucose tolerance and dyslipidaemia. Kabat et al. demonstrated a positive association between metabolic syndrome and breast cancer [16]. Population studies have shown that metformin is associated with a significant reduction of breast cancer risk [17].

Metabolic syndrome and mammographic breast density seem to represent independent risk factors for breast cancer. A recent study has demonstrated an inverse correlation between metabolic syndrome and breast density in pre- and early perimenopausal women [18]. Adiposity and increased glucose levels were significantly inversely correlated with breast density. This observation confirms the role of obesity as a factor associated with decreased risk of breast cancer incidence in premenopausal women. Actually, only in the context of the above observation can we discuss the results of our own study, since in the literature there are virtually no data on the correlation of mammographic breast density with sonographic breast elasticity.

In our study we have analysed the correlation of breast elasticity in premenopausal women with various metabolic parameters. We have demonstrated an inverse correlation between insulin levels, HOMA index and breast heterogeneity, which meant that breast fatty tissue homogeneity increased with increasing insulin resistance. No such correlation was observed with respect to glandular tissue.

As Conroy et al. have demonstrated, mammographic breast density was decreased in otherwise healthy premenopausal women presenting with obesity or increased fasting glucose levels [18]. In our study, in a similar population the above-mentioned metabolic parameters significantly correlated with increased homogeneity of breast fatty tissue. As mentioned above, increasing amounts of fatty tissue result in decreased mammographic breast density. Accordingly, one may assume that increased homogeneity of breast fatty tissue may represent a surrogate indicator of decreased mammographic breast density.

Samani et al. [19] discussed the heterogeneity of breast tissue in the context of breast tumours. Heterogeneity in Young's modulus variability was observed both in visual and pathological assessment using a microscope in tumours. They often consist of piecewise homogeneous abnormal tissues with pockets of normal tissues randomly distributed. This potentially could represent increased elasticity heterogeneity of tumours and other tissue measures in sonoelastography [19]. There is only one clinical study marginally dealing with breast elasticity heterogeneity measured by shear wave technique. The only observation was that lower SD values (as in our study: minimum-maximum heterogeneity and derivative parameters) were typical for normal tissue and higher for cancers [20].

There are several questions related to the importance of the phenomenon observed in our study. It is possible that evaluation of breast elasticity in the context of insulin resistance may provide some information on the risk of development and eventually progression of breast cancer in premenopausal women. It might also represent a predictive factor in breast cancer management and an argument for metformin therapy [6]. Chala et al. found that in postmenopausal breast cancer patients the response to chemotherapy correlated with decreased insulin levels [5].

Furthermore, the pilot nature of our study resulted in the first, to our knowledge, presentation of data linking quantitative breast elasticity measured by share wave sonography and obesity, insulin and insulin resistance as selected breast cancer risk factors. In order to profoundly explore such a relatively new technique as shear wave sonography, one must not only estimate its diagnostic power but also evaluate sonoelastographic findings in the context of physiology and pathology of the breast. The B-mode ultrasound was also evaluated in relation to these parameters and plays a huge role in clinical practice nowadays.

Unfortunately, in our study we could not compare standard mammography with sonoelastography because of the relatively young age and lack of indications for mammography in our patients. In Poland, screening mammography in the standardrisk population is only recommended for women aged 50 years and above. However, such a study 
directly comparing mammography and sonoelastography in patients at high risk of breast cancer (e.g. in BRCA1, breast cancer type 1 susceptibility protein mutation carriers) is warranted.

In conclusion, insulin levels and insulin resistance correlate with breast fat tissue heterogeneity, but their role in breast pathology remains unclear.

\section{Acknowledgments}

The authors thank the radiologist Agnieszka Skórzewska MD PhD for cooperation and help with elastography methodology.

\section{References}

1. Weinstein D, Simon M, Yehezkel E, Laron Z, Werner H. Insulin analogues display IGF-I-like mitogenic and antiapoptotic activities in cultured cancer cells. Diabetes Metab Res Rev 2009; 25: 41-9.

2. Augustyn LSA, Dal Maso L, La Vecchia C, et al. Dietary glycemic index and glucose load, and breast cancer risk: a case-control study. Ann Oncol 2001; 12: 1533-8.

3. Diorio C, Pollak M, Byrne C, et al. Insulin-like growth factor-1, IGF-binding protein-3 and mammographic breast density. Cancer Epidemiol Biomarkers Prev 2005; 14: 1065.

4. Wysocki PJ, Wierusz-Wysocka B. Obesity, hyperinsulinemia and breast cancer: novel targets and a novel role for metformin. Expert Rev Mol Diagn 2010; 10: 509-19.

5. Chala E, Manes C, Iliades H, Skaragkas G, Mouratidou D, Kapantais $E$. Insulin resistance, growth factors and cytokine levels in overweight women with breast cancer before and after chemotherapy. Hormones 2006; 5: $137-46$.

6. Akin F, Bastemir M, Alkiș E, Kaptanoglu B. SHBG levels correlate with insulin resistance in postmenopausal women. Eur J Intern Med 2009; 20: 162-7.

7. Malin A, Dai Q, Yu H, et al. Evaluation of the synergistig effect of insulin resistance and insulin-like growth factors on the risk of breast carcinoma. Cancer 2004; 100: 695-700.

8. Harvey JA, Bovbjerg VE. Quantitative assessment of mammographic breast density: relationship with breast cancer risk. Radiology 2004; 230: 29-41.

9. Byrne C, Colditz GA, Willett WC, Speizer FE, Pollak M, Hankinson SE. Plasma insulin-like growth factor (IGF) I, IGFbinding protein 3 , and mammographic density. Cancer Res 2000; 60: 3744-8.

10. Maskarinec G, Williams AE, Kaaks R. A cross-sectional investigation of breast density and insulin-like growth factor I. Int J Cancer 2003; 107: 991-6.

11. Wolin KY, Colangelo LA, Chiu BC, Ainsworth B, Chatteron R, Gapstur SM. Associations of physical activity, sedentary time and insulin with percent breast density in Hispanic women. J Womens Health 2007; 16: 1004-11.

12. Diorio C, Pollak M, Byrne C, et al. Levels of C-peptide and mammographic breast density. J Cancer Epidemiol Biomarkers Prev 2005; 11: 2661-4.

13. Verheus M, Peeters PH, Rinaldi S, et al. Serum C-peptide levels and breast cancer risk: results from the European Prospective Investigation into Cancer and Nutrition (EPIC). Int J Cancer 2006; 119: 659-67.

14. Eliassen AH, Tworoger SS, Mantzoros CS, Pollak MN, Hankinson SE. Circulating insulin and c-peptide levels and risk of breast cancer among predominately pre- menopausal women. Cancer Epidemiol Biomarkers Prev 2007; 16: 161-4.

15. Cust AE, Stocks T, Lukanova A, et al. The influence of overweight and insulin resistance on breast cancer risk and tumour stage at diagnosis: a prospective study. Breast Cancer Res Treat 2009; 113: 567-76.

16. Kabat GC, Kim M, Chlebowski RT, et al. A longitudinal study of the metabolic syndrome and risk of postmenopausal breast cancer. Cancer Epidemiol Biomarkers Prev 2009; 18: 2046-53.

17. Papanas N, Maltezos E, Mikhailidis DP. Metformin and cancer: licence to heal? Expert Opin Investig Drugs 2010; 8 : 913-7.

18. Conroy SM, Butler LM, Harvey D, et al. Metabolic syndrome and mammographic density: the study of women's health across the nation (SWAN). J Cancer 2010 Nov 23. [Epub ahead of print].

19. Samani A, Zubovitts J, Plewes D. Elastic moduli of normal land pathological human breast tissues: an inversiontechnique-based investigation of 169 samples. Phys Med Biol 2007; 52: 1565-76.

20. Evans A, Whelehan P, Thomson K, et al. Quantitative shear wave ultrasound elastograpgy: initial experience in solid breast masses. Breast Cancer Res 2010; 12 104-14. 